\title{
ACL Revision Surgery with Autografts and Allografts: A Comparative Study
}

\author{
Adriano Marques de Almeida*, Nuno Martins, André Pedrinelli and Arnaldo José Hernandez \\ Department of Orthopedics and Traumatology, University of São Paulo- São Paulo, Brazil \\ *Corresponding author: Adriano Marques de Almeida, Department of Orthopedics and Traumatology, University of São Paulo, Postal code: 05403-010, \\ Brazil
}

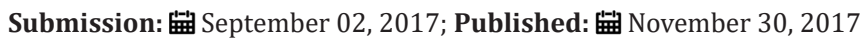

\section{Introduction}

Anterior cruciate ligament (ACL) reconstruction is one of the most common surgical procedures in orthopedics [1], and the number of ACL revision surgeries is increasing concomitantly [2]. ACL revision surgery is more technically demanding and final results are less satisfactory than primary surgeries [2]. In the ACL revision surgery both autografts or allograft can be used [3]. The choice is related to the surgeon's experience and donor site morbidity. The autografts more commonly used are bone-patellar tendon-bone (BРTB) or hamstrings. Considering the primary ACL reconstruction, they have shown satisfactory strength and incorporation [4], and better results compared to the allograft, but there is insufficient data about the results of revision ACL surgery with the use of allografts. However, in ACL revision cases, donor site morbidity may be a problem, mainly in second or third revisions. The purpose of this study is to evaluate the results of ACL surgery comparing the results of cases in which autografts or allografts have been used.

\section{Methods}

Patients submitted to ACL revision surgery were retrospectively evaluated. All patients had the diagnosis of ACL reconstruction failure confirmed by clinical examination and MRI assessment. The protocol was approved by the institutional IRB. The autografts were frozen, non-irradiated, following the standards of the American Association of Tissue Banks. The final outcome was the presence or absence of the pivot-shift test. We compared the results using the Fisher exact test.

\section{Results}

Fourteen patients were included, with average follow-up of 19.7 months. Nine patients were male (six in the autograft group and three in the allograft group). Autografts were used in eight cases and allografts were used in six cases. Average age was 24.8 years old (19.3y.o. in the autografts group and 29y.o. in the allograft group). Considering the six cases in which allograft have been used, BPTB allograft was used in five cases and anterior tibiallis in one case. Considering the eight cases in which autografts have been used, BPTB autografts were used in five cases and hamstrings in three cases. Pivot-shift test was positive in one case and absent in seven cases of autografts group. Pivot-shift test was present in five cases and absent in one case of allograft group (Fisher exact test, $\mathrm{p}=.026)$.

\section{Discussion}

Allografts are more commonly used in ACL revision surgeries than in the primary surgery [5]. Potential advantages are no donor site morbidity, less pain, and faster recovery. However, there is a concern regarding their healing potential and mechanical properties. A metanalysis has shown a 3 fold rate of failure in primary ACL cases with allografts compared to autografts $[6,7]$. Gorchewsky et al observed a failure rate in six years of $5.9 \%$ with autografts and $44.7 \%$ with allograft [8], and Singhal reported a reoperation rate of $38 \%$ in patients with less than 25 years old with the use of allograft [9]. The results of revision ACL tend to be poorer than the results of primary ACL surgeries, with failure rates up to $24 \%$ [10]. Pivot-shift test is considered the most specific to ACL insufficiency diagnosis [11-13]. Pivot-shift test results are related to patient's satisfaction, symptoms and sports participation $[14,15]$. It is more associated with clinical results than the Lachman test [15-17]. The correlation between pivot-shift and functional scores has been reported as $85 \%$ [14].

The pivot-shift is a subjective test, and, although it has been divided accordingly to its severity, the classification in present or absent is more reproducible and trustworthy $[11,13,16]$. In this study, we observed a positive pivot-shift in the majority of patients operated with allograft and in only one case operated with autografts. All surgeries were performed by the same surgeons; therefore, the possibility of differences in technical errors is low, and much of the results can be attributed to the graft used. The average age of patients in the allograft group was 19 years old. Therefore, in the young, active patient, autografts would be a better choice for ACL revision surgery.

\section{Conclusion}

Post-operative results of ACL revision surgery with autografts were better in terms of knee stability than the results with 
allograft. In the active, young patient, allograft showed a high rate of persistent instability. The use of autografts showed to be a better option in these cases.

\section{References}

1. van Eck CF, Schkrohowsky JG, Working ZM, Irrgang JJ, Fu FH, et al. (2012) Prospective Analysis of Failure Rate and Predictors of Failure After Anatomic Anterior Cruciate Ligament Reconstruction With Allograft. Am J Sports Med 40(4): 800-807.

2. Ahn JH, Lee YS, Chang MJ, Yim HS (2011) Analysis of Revision Anterior Cruciate Ligament Reconstruction according to the combined injury, degenerative change, and MRI findings. Knee 18(6): 382-386.

3. Rice RS, Waterman BR, Lubowitz JH (2012) Allograft versus Autograft Decision for Anterior Cruciate Ligament Reconstruction: An ExpectedValue Decision Analysis Evaluating Hypothetical Patients. Arthroscopy 28(4): 539-547.

4. Barrett GR, Luber K, Replogle WH, Manley JL (2010) Allograft anterior cruciate ligament reconstruction in the young, active patient: Tegner activity level and failure rate. Arthroscopy 26(12): 1593-1601.

5. MARS Group, Wright RW, Huston LJ, Spindler KP, Dunn WR, et al. (2010) Descriptive epidemiology of the Multicenter ACL Revision Study (MARS) cohort. Am J Sports Med. 38(10): 1979-1986.

6. Prodromos C, Joyce B, Shi K (2007) A meta-analysis of stability of autografts compared to allografts after anterior cruciate liga- ment reconstruction. Knee Surg Sports Traumatol Arthrosc 15(7): 851-856.

7. Penn D, Willet TL, Glazebrook M, Snow M, Stanish WD, et al. (2009) Is there significant variation in the material properties of four different allografts implanted for ACL reconstruction. Knee Surg Sports Traumatol Arthrosc 17(3): 260-265.

8. Gorschewsky O, Klakow A, Riechert K, Pitzl M, Becker R, et al. (2005) Clinical comparison of the Tutoplast allograft and autologous patellar tendon (bone-patellar tendon-bone) for the reconstruction of the anterior cruciate ligament: 2- and 6-year results. Am J Sports Med 33(8): $1202-1209$

9. Singhal MC, Gardiner JR, Johnson DL (2007) Failure of primary anterior cruciate ligament surgery using anterior tibialis allograft. Arthroscopy 23(5): 469-475.

10. George MS, Dunn WR, Spindler KP (2006) Current concepts review: revision anterior cruciate ligament reconstruction. Am J Sports Med 34(12): 2026-2037.

11. Musahl V, Hoshino Y, Ahlden M, Araujo P, Irrgang JJ, et al. (2012) The pivot shift: a global user guide. Knee Surg Sports Traumatol Arthrosc 20(4): 724-731

12. Benjaminse A, Gokeler A, van der Schans CP (2006) Clinical diagnosis of an anterior cruciate ligament rupture: a meta-anal- ysis. J Orthop Sports Phys Ther 36(5): 267-288

13. Tanaka M, Vyas D, Moloney G, Bedi A, Pearle AD, et al. (2012) What does it take to have a high-grade pivot shift? Knee Surg Sports Traumatol Arthrosc 20(4): 737-742.

14. Ayeni OR, Chahal M, Tran MN, Sprague S (2012) Pivot shift as an outcome measure for ACL reconstruction: a systematic review. Knee Surg Sports Traumatol Arthrosc 20(4): 767-777.

15. Kocher MS, Steadman JR, Briggs KK, Sterett WI, Hawkins RJ (2004) Relation- ships between objective assessment of ligament stability and subjective assessment of symptoms and func- tion after anterior cruciate ligament reconstruction. Am J Sports 32(3): 629-634.

16. Lane CG, Warren R, Pearle AD (2008) The pivot shift. J Am Acad Orthop Surg 16(12): 679-688.

17. Leitze Z, Losee RE, Jokl P, Johnson TR, Feagin JA (2005) Implications of the pivot shift in the ACL-deficient knee. Clin Orthop Relat Res 436: 229236. 